\title{
Study on the Connection between Tourism English Translation and Local Culture
}

\author{
Shunyuan Zhang, Zhiqiang Sun, Xin Jin \\ Tourism school of Kunming University, Kunming, Yunnan, 650000
}

Keywords: Tourism English, Local Cultural, Connection Method

\begin{abstract}
Tourism is a modern service industry that integrates ideological and cultural exchanges and economic activities. With the globalization of the economy, tourism is rapidly developing. As a service industry with ideological and cultural exchange as the core, there are often problems in cultural communication barriers in tourism English translation, especially in the translation of some localized proper nouns and the translation of cultural phenomena. These aspects are more obvious. To a different extent, it hinders the development of tourism and the spread of ideology and culture. Tourism English translation in the new era should not be too rigid or "cottage", but should seek breakthroughs through the reasonable integration of tourism English and local culture.
\end{abstract}

\section{Introduction}

In recent years, with the continuous development of economic globalization, cooperation and exchanges between countries have continued to deepen. Tourism is an important way of cultural exchange. Through the visit to foreign attractions, you can deeply understand the historical and cultural symbols contained in it, which is of great significance to the cultural exchange between countries. Due to the long history of China and the complex and ever-changing nature of local culture, it often hinders the use of tourism English because of some localized words or cultural phenomena, which leads to obstacles in cultural communication and is not conducive to the tourism industry. development of. Therefore, how to link local culture with tourism English has become an important means to solve this problem and an important way to promote the development of tourism.

\section{Reasons for the translation of English translation and local culture}

Translation is a tool of language communication between two kinds of society, but in the process of translation, it is difficult to solve the problem of cultural differences by using only text skills. Any translation is inseparable from culture. In particular, the English translation of tourism contains a large number of historical allusions and idioms. During the tour, it is translated into idioms and historical allusions in different languages. It is necessary to understand the history and culture. In order to be just right, many experienced foreign language guides or translators pay more attention to the relationship between tourism translation and local culture.

Chinese language pays attention to the harmony and overall unity of language. The sentence structure is centered on verbs and expressed in time as logical order. English sentence patterns are often composed of subject and predicate, composed of multiple phrases and clauses. And the meaning. The differences in Chinese and Western language thinking habits and expressions determine the differences in sentence patterns, sentence formation, and sentence ellipsis during translation. If you simply translate it literally, it will make the language structure confusing, rigid, and unorganized. For example, foreign language guides commonly use the phrase "Fuzhou welcomes you", the common translation is "welcome to Fuzhou", the sentence is changed when using the sentence, the English imperative sentence is used, such as literal translation "Fuzhou is welcome you", the effect is Great discount. Social customs and habits are the expression of the diversity of ethnic activities and the embodiment of a national character. Customs are very common, and they are used in daily social and communicative activities, and are reflected in many aspects 
such as diet, marriage and burial. Different ethnic groups naturally have different social customs. In the immigration tourism activities, the freshness of tourists comes from the differences of customs in the other society. Accurate tourism translation can not only enhance the tourism experience, but also eliminate the communication barriers caused by social customs differences. For example, "red" symbolizes "joy and auspiciousness" in Chinese culture, while "red" in English is always associated with bad things such as bloodshed and martyrdom. Another example is that Chinese people despise dogs, so there are words such as "going dogs", "dog things" and "dogs looking low". In Western countries, people appreciate the courage and loyalty of dogs, and often compare people to dogs, such as "a lucky dog." "(Lucky), "Every dog has his day" and so on. Different meanings of words caused by these different social customs must pay special attention to tourism translation.

\section{Characteristics of travel English translation}

In the process of using travel English, you can't just use travel English as a tool to communicate with foreigners, but as a way of communicating with foreigners. It is necessary to learn about the history and culture of China by letting foreigners know the history and culture of the places they visit. For example, when translating the Forbidden City, the word "purple" is not color, but refers to auspicious, but in foreign cultural systems, the meaning of color will be different, so if there is no corresponding attention and solution, It is easy to cause foreigners to have a bias in understanding our culture, which affects the effects of cultural exchanges at home and abroad.

Rhetoric is a form of language that modifies speech and complements and explains the description. Most of the tourists who travel across the country want to know the customs of other countries. Therefore, in the travel English, through rhetoric, visitors can have a more three-dimensional understanding of the attractions and their history and culture, and enhance the tourists' harvest. Improve the quality of travel. The history and culture of our country are rich, and many scenes are reflected in the poems. For example, in the phrase "Guilin's landscape is the best in the world", if you simply translate the world into the world, it will not only lose the original cultural heritage, but also cause tourists to have doubts in the process of understanding. It is not clear why Guilin's landscape can be the best in the world. . Therefore, the reasonable translation of rhetoric can not only reflect the richness of Chinese culture, but also better reflect the history and culture of the scenic spot.

\section{The status quo of tourism English translation and local culture}

In different countries, a vocabulary may have different meanings. For example, the meaning of dragon in the Chinese and Western is different. In China, the dragon is a kind of creature that symbolizes auspiciousness and dignity. It is usually used to represent the emperor. The emperor often calls himself a true dragon, sitting in a dragon chair, wearing a robes, and a western dragon. An evil and cruel creature, plundering wealth, burning people, and often appearing as a villain in Western literature. Another example is the word purple, translated into purple. In the traditional Chinese culture, purple has the meaning of solemn auspicious, while in English it is more of a color expression. In the process of translation of travel English, there is usually no additional emphasis on such vocabulary, and direct translation is directly caused, which has led to the phenomenon of difficulty in understanding foreign tourists.

Due to the different geographical location, development status and history of each country, its cultural heritage is also different and different. Whether it is diet or thought, or spiritual level, it will be different. Because China has a profound history of 5,000 years, the cultural heritage is extremely rich, which is the main reason why foreigners come to China for tourism. Due to the cultural differences between countries, many Chinese cultural phenomena will have meaning deviations in the process of translating through travel English, and even the opposite situation will appear. In many cases, due to improper translation of translators, Let tourists have serious misunderstandings about the content they are visiting, which not only affects the tourist experience, but also affects the cultural exchanges between countries. 


\section{Strategies for the Interaction between Tourism English Translation and Local Culture}

The background of tourism English translation work is to explain the scenic spots and local folk customs to tourists in a relatively unfamiliar place. These are inseparable from the understanding and analysis of local historical allusions. From a certain point of view, in order to allow visitors to have a certain understanding of the local scenic spots and folk customs, it is necessary to translate the local historical allusions and English translations in place.

For example, many foreign tourists will visit the famous Hanshan Temple in Jiangsu Province. Here, not only the scenery is good, but also the historical background and cultural accumulation. The tour guide will introduce the Hanshan Temple to the tourists with the poem "Maple Bridge Night Park". The poems of the slogans are supplemented by the English translations in place, which will enable tourists to be quickly infected by the strong cultural background of Hanshan Temple. They can't help but mention the various aspects of Hanshan Temple in the past 100 years. When introducing Hanshan Temple, it is necessary to use it to create a background for English translation. This temple was named after a monk named "Hanshan" in the Tang Dynasty, so it cannot be translated literally as "the Bleak Mountain". Or "GoldMountain Temple", but should be translated as "Hanshan Temple" according to the name of its name. [5] Similarly, the explanation of the verses about Hanshan Temple should also be explained in accordance with the translation of the above-mentioned translated names. When explaining, it must follow the historical track slowly, and the original historical allusions can always immerse tourists. In the long history of the river, let visitors first understand the origin of the name of Hanshan Temple, and will not let tourists feel strange and puzzled because there is no such word as "Hanshan" in English. For example, when introducing the ancient capital of Xi'an, which has a long history, it will use the poems of the Tang Dynasty's "East and West City in the City, Wenke Diying”. From the perspective of the literati of the ages, the city of Xi'an was in the Tang Dynasty. There is a strong cultural, commercial and political atmosphere. The "East" refers to the place where the palace is located. The politics, economy and culture are at the peak, and "West" refers to the bustling streets and streets of Taiping. It is imperative that the "West-West City" in the verse should not be translated as "east and west". This kind of translation is very easy for visitors to simply interpret the description of Xi'an in the verse as "East" and "West". The original description of the prosperous scene of the verse is limited to the visual orientation.

China's traditional culture has a long history. No matter what scenic spots or cultural customs, there are many proper nouns. The translation of these proper nouns is a cultural mastery and connotation conversion that tests the translator's grasp of grammar and sentence structure. A level of ability. When visiting places of interest, tourists often have an interest in local cuisine. Understanding the food is an important part of the rich cultural heritage of our country. In particular, the names of dishes with beautiful meanings such as "Xiyu Yingchun" and "Phoenix Spreading Wings" should be fully displayed in the name of translation in the name of "Pear Magpie welcome thespring" and "Phoenix spread the wings". "Let the tourists taste the food, but also deeply understand the mood and background beauty conveyed by different foods.

Folk customs have always been a highlight of attracting tourists. When telling tourists about local customs, they must not be translated or translated. For example, when introducing the Dragon Boat Festival and Mid-Autumn Festival, it cannot be translated as: "Dragon - Boat Festival" and "Moon - cake Festival", although let visitors know the customs and habits of people in the festival, but this translation habit will make visitors pay attention to the holiday customs, and ignore the festival. Reasons and meanings, so we should avoid the habit of translating festival customs into festival names, and translate the Dragon Boat Festival and Mid-Autumn Festival into "Double Fifth Day" and "Mid - Autumn Day", according to the period of the festival. Compared with simply translating according to holiday customs, visitors are naturally more willing to know why these festivals have cultural connotations at this time. 


\section{Conclusion}

China's vast land and resources, since ancient times, the number of scenic spots and countless, thousands of scenic spots, all kinds of scenic spots, food, food and customs are built on the civilization that has been passed down for thousands of years, whether it is the translation of place names, the translation of food, the translation of customs, festivals The translation is also the translation of historical allusions. It is necessary to put the cultural connotation and spirit of the festival in the first place of communication. Using the most appropriate translation to let foreign friends truly understand Chinese civilization is the ultimate goal of tourism English translation.

\section{References}

[1] Zong Xiaohui. Research on the relationship between tourism Ying Ningyu translation and local culture [J]. Art Communication, 2014, 3(12): 177-178.

[2] Li Yulin, Reflections on the Connection between Tourism English Translation and Local Culture [J].Journal of South China University of Tropical Agriculture,2006,12(1):16-17.

[3] Luo Lingjiang, Chen Yu. Analysis of the multi-functional value of English translation in the development of tourism economy [J]. China Business, 2012, 17 (9): 92-93.

[4] Zhang Xiaowei. The combination of local culture in Sichuan and the teaching of tourism English in the province [J]. Journal of Sichuan College of Education, 2010, (1).

[5] Zhou Meizhi. A Probe into the Incorporation of Local Cultural Features in Tourism English Training Course-Taking Guangxi Foreign Language College as an Example [J]. Campus English, 2012, (6). 